\title{
Article \\ Time-Domain Dynamic Modeling and Analysis of Complex Heavy-Duty Gearbox Considering Floating Effect
}

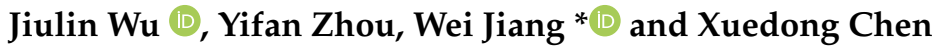 \\ State Key Laboratory of Digital Manufacturing Equipment and Technology, Huazhong University of Science and \\ Technology, 1037 Luoyu Road, Wuhan 430074, China; wuj@@hust.edu.cn (J.W.); yifanzhou@hust.edu.cn (Y.Z.); \\ chenxd@hust.edu.cn (X.C.) \\ * Correspondence: jiangw@hust.edu.cn; Tel.: +86-13995632257
}

Citation: Wu, J.; Zhou, Y.; Jiang, W.; Chen, $X$. Time-Domain Dynamic Modeling and Analysis of Complex Heavy-Duty Gearbox Considering Floating Effect. Appl. Sci. 2021, 11, 6876. https://doi.org/10.3390/ app11156876

Academic Editors: Javier Poza, Gaizka Almandoz and Gaizka Ugalde

Received: 30 June 2021

Accepted: 24 July 2021

Published: 26 July 2021

Publisher's Note: MDPI stays neutral with regard to jurisdictional claims in published maps and institutional affiliations.

Copyright: (c) 2021 by the authors. Licensee MDPI, Basel, Switzerland. This article is an open access article distributed under the terms and conditions of the Creative Commons Attribution (CC BY) license (https:// creativecommons.org/licenses/by/ $4.0 /)$.
Featured Application: The proposed time-domain dynamic modeling method can be applied to analysis and design of heavy-duty gearboxes in wind turbines, cranes, drilling rigs and so on.

\begin{abstract}
Expert insights into the time-domain dynamic behavior of heavy-duty gearboxes form the foundations of design evaluation and improvement. However, in the existing lateral-torsional coupling (LTC) modeling method for gearboxes that is normally used for frequency-domain dynamic behavior, the meshing forces are modeled as spring dampers with fixed acting points on the meshing gears to simulate only the transient LTC effect, and thus the steady state characteristic in the time domain cannot be obtained due to the unrealistic distortion of positions and orientations as the gear angles increase. In this paper, a novel and generally applicable LTC modeling method for heavy-duty gearboxes, mainly planetary gear sets with floating components, is proposed by using space-fixed spring dampers with floating acting points on the meshing gears to study the timedomain dynamic response and to support the dynamic design of heavy-duty gearboxes. Based on the proposed method, a LTC model of a 2 megawatt (MW) wind turbine gearbox with floating components considering the time-varying meshing stiffness, bearing stiffness, torsional stiffness, and floating effect was established. The simulated results of representative components were in accordance with experimental results on a test rig, and dynamic behavior was calculated.
\end{abstract}

Keywords: heavy-duty gearbox; dynamic design; time-domain; lateral-torsional coupling; floating effect

\section{Introduction}

Gear systems are the most significant and extensively adopted mechanical transmission devices in modern applications such as automobile, locomotive, mining, metallurgy, electric power, petroleum and chemical industries. As mechanical equipment tends to develop in the direction of larger scale and higher performance, gear systems with high power, high speed and heavy load are in great demand. The working environment for gear transmission systems is extremely complex, especially for the heavy-duty gearboxes adopted in large ships, offshore platforms, wind power machines, etc. There exist not only external incentives introduced by the variable load condition and power plant, but also internal incentives from the time-varying meshing stiffness, the gear transmission error, the meshing impact, etc. Taking the wind turbine gearbox (WTG) as an example, as the drivetrain that connects the rotor hub with the generator converts the wind energy into electrical energy, the wind field turbulence through the hub and the electricity grid disturbance through the generator become the external excitations [1]. Meanwhile, since most WTGs contain planetary gear sets with floating components because of the advantages of compact structure, high power density, and coaxial arrangement of transmission shafts [2], the varying mesh stiffness, meshing incentive, impact of floating components, and composition error generate the internal excitations $[3,4]$. These make the service condition of WTGs 
quite unique and rigorous. The service life of a wind turbine is usually designed to last more than 20 years [5]. However, internal WTGs have the highest failure rate of all wind turbine components [6,7], and the main cause of wind turbine standstill is the vibration issue [8]. Hence, the dynamic behavior and working performance of gearboxes have a significant impact on the whole machine, and research on the vibration characteristics is critical to the design and redesign of gearboxes.

Considerable efforts have been made to give comprehensive insights into the dynamic behavior and vibration issues of gearboxes, especially of planetary gear sets $[9,10]$. Kahraman et al. [11] derived a time-varying dynamic model of a planetary transmission including the manufacturing error, assembly variation and time-varying stiffness. Lin and Parker et al. [12] developed an analytical lumped-parameter model of a planetary gear set and used it to investigate the natural frequencies and vibration modes. Abousleiman et al. $[13,14]$ investigated the vibration behavior of a planetary gear set with an elastic ring gear and an elastic planet carrier. Chen and Shao [15] derived a mesh stiffness model of an internal gear pair with a tooth root crack in the ring gear based on the potential energy principle. Christopher et al. [16] proposed a finite element formulation for the dynamic response of gear pairs. Maláková et al. [17] analyzed the main influencing factors on the meshing stiffness, as changes in the stiffness are a significant source of noise and vibration. She also designed a non-circular gear transmission system with continuously changing gear ratio and studied its kinematical characteristics [18]. Girsang et al. [19] studied the dynamic response of a WTG by enhancing the capability of FAST (a wind turbine CAE tool) [20] through the integration of a gearbox model built using Simscape, which took into account excitations from both the wind field and the generator. Zhu et al. [21,22] used the lumped parameter method to study the dynamic behavior of a WTG with flexible pins and proved that the flexible pins can improve the load sharing ability. Park et al. [23] investigated the influence of non-torque loads on the dynamic behavior of planetary gears, including the loading distribution and loading sharing, and concluded that considering the non-torque load during the design stage is quite important to accurately determine the design load that will guarantee the service life of a WTG.

In large-scale mechanical systems, heavy-duty gearboxes with planetary gear sets are adopted extensively due to their unique advantages of high power density and high transmission ratio; however, this yields complex configurations and characteristic serving circumstances. Thus, more stringent design criteria are desired than for common industrial gearboxes, and the dynamic forces become the major limiting factor to achieving better performance [24]. In previous studies concerning gearboxes, the assessment of dynamic behavior is usually centered on the frequency domain. Hence, a study of dynamic behavior in the time domain becomes significant, as it can confirm the dynamic loading factors, which are usually chosen by experience from a manual according to the traditional design code for common gearboxes. In this paper, an appropriate and generally applicable modeling approach of heavy-duty gearboxes, mainly the planetary gear set, is proposed to investigate dynamic behavior in the time domain, and a LTC model of a 2 MW WTG was built in which the time-varying meshing stiffness, bearing stiffness, torsional stiffness, and floating factor were considered. The model was then verified by experiments on a test rig, and dynamic characteristics of the WTG were finally revealed on the verified model.

\section{LTC Modeling Approach of Heavy-Duty Gearbox}

To establish a dynamic model of a heavy-duty gearbox, modeling of a planetary gear set with floating components serves as the most basic as well as the most significant portion. This is mainly because common gear transmissions can be simplified or derived from planetary gear sets. Therefore, a planetary gear set model will be highlighted and introduced as a representative basis in this section. 


\subsection{LTC Models of Planetary Gear Set}

Interactive incentives between the gear engagements occur mainly through the meshing forces. The existing LTC model of a planetary gear set is shown in Figure 1a. The translation flexibility is simplified as linear spring dampers in the $\mathrm{XY}$ plane, while the flexibility between gear engagement, which is mainly caused by bending deflections and contact deformations of gear teeth, is simplified as a spring damper with equivalent average stiffness along the line of engagement with fixed acting points $[12,15,25-30]$. Thus, each component is modeled with three degrees of freedom (DOF), and the bearing stiffness and time-invariant meshing stiffness are considered. This method has an inherent defect in that only small angular displacements of gears are permitted, and thus only the transient vibration characteristic of gear pairs can be solved and obtained.

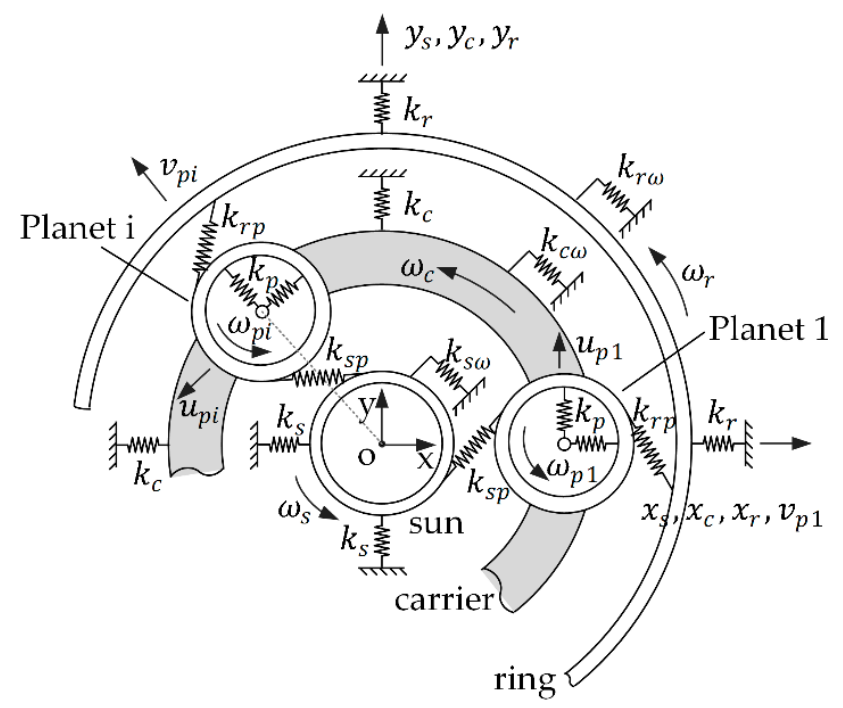

(a)

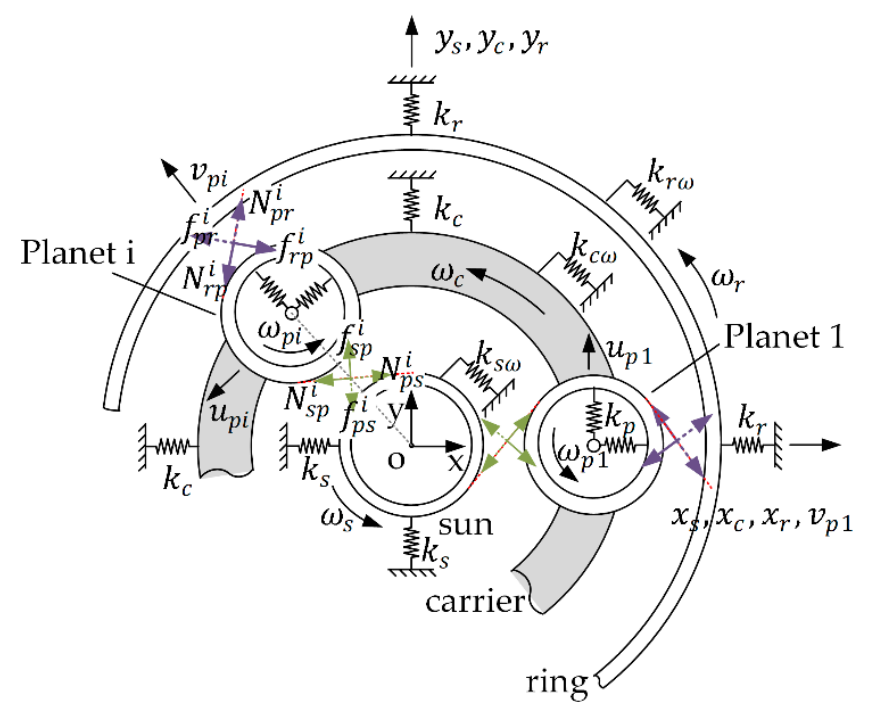

(b)

Figure 1. LTC modeling of a planetary gear set: (a) using the existing method (b) using the proposed method.

This paper proposes a novel method for LTC modeling. The elasticity and viscidity of gears, carriers, shafts, bearings, etc., are represented by time-varying stiffness-damping forces, while the bodies of gears, carriers and shafts are all modeled as rigid elements. Thus, a final multibody system of the gear set with consideration of time-varying stiffness, friction, damping, etc. is established. Based on Newton's third law, the interaction of two bodies can be represented by an action force and an opposite reaction force that are functions related to the corresponding characteristic parameters of the two bodies. According to the basic law on parallel translation of force, forces on the contact point are equal to the combined effects of component force in $X Y$ plane and component torque around the $\mathrm{Z}$ axis in the center. With these proper transformations, the meshing effect can be modeled as a normal pressure force, represented by a time-varying stiffness spring damper force, and a tangential force, represented by a synthesis of a viscous damping force and a coulomb friction force (Figure 1b). These two kinds of force can eventually be replaced by time-varying component forces and torques with respect to the generalized coordinates on gear centers of the input and output gears respectively. Hence, large angular displacements of gears are allowed, and the entire coupling model can be utilized for the calculation of system dynamic behavior in the time domain.

The proposed method operates as space-fixed spring dampers with floating acting points, which guarantees that the positions and orientations of spring dampers coincide with the actual meshing forces regardless of changes in the centroids or the angles of the meshing gears. The proposed method is compared with the existing method in Table 1. 
Table 1. Comparison of existing and proposed method.

\begin{tabular}{ccc}
\hline Methods & Existing Method & Proposed Method \\
\hline Frequency-domain behavior & $\sqrt{ }$ & $\sqrt{ }$ \\
Transient time-domain behavior & $\sqrt{ }$ & $\sqrt{ }$ \\
Continuous time-domain behavior & $\times$ & $\sqrt{ }$ \\
\hline
\end{tabular}

\subsection{Detailed Formulations}

Due to the unique status of the planetary gear set in heavy-duty gearboxes, detailed formulations of LTC dynamic equations of a planetary gear set with floating components are emphasized. Each object in the planetary gear set is modeled with three DOFs. The translational displacements and rotational angle are chosen as the generalized coordinates:

$$
\begin{aligned}
& \left(x_{b}, y_{b}, \theta_{b}\right) \quad \text { while, } b=R, S \text { and } C \\
& \left(x_{b}^{i}, y_{b}^{i}, \theta_{b}^{i}\right) \quad \text { while, } b=P_{i}(i=1,2, \ldots, n)
\end{aligned}
$$

in which $R$ is the ring gear, $P$ is the planet gear, $S$ is the sun gear, and $C$ is the planet carrier.

A schematic diagram of a force analysis of the whole gear set is shown in Figure 2. The reaction forces on the $i$ th planet gear include $N_{R P}^{i}$ and $f_{R P}^{i}$, the normal pressure force and tangential force that the ring gear exerts; $N_{S P}^{i}$ and $f_{S P}^{i}$, the normal pressure force and tangential force that the sun gear exerts; and $F_{C P}^{i}$ and $T_{C P}^{i}$, the reaction force and reaction torque from the bearing. Force analyses of the ring gear and the sun gear can be presented in the same way, which consist of the meshing forces and the reaction bearing forces if they exist.

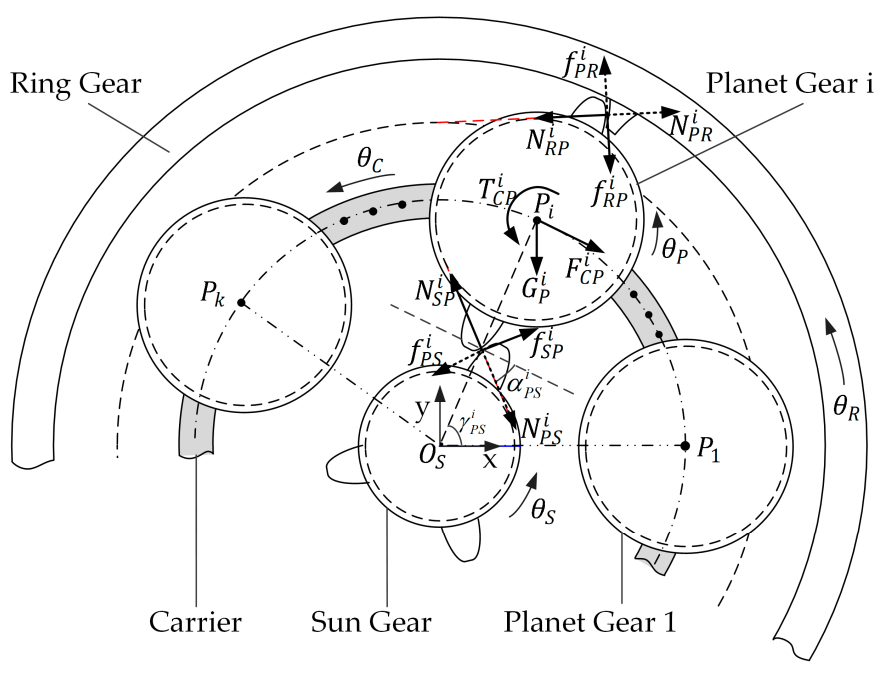

Figure 2. Force analysis of the planetary gear set.

\subsubsection{Force Derivation of the Engagement of the Sun and ith Planet Gears}

The composite deformation in normal and tangent directions of a meshing can be obtained from the generalized displacements; thus, the normal force $N$ and tangent force $f$ are derived. As shown in Figure 3, two main influencing factors exist: the difference between the actual and the ideal angle, and the time-varying center distance between the sun and planet gear that is mainly introduced by the floating components. 


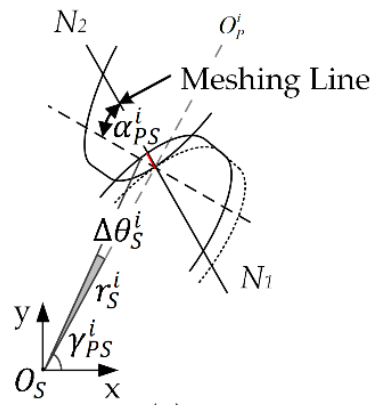

(a)

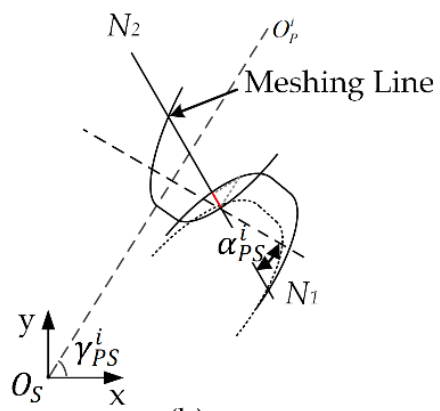

(b)

Figure 3. Composite deformation between the sun and ith planet gear: (a) deformation from angle difference: $\delta_{\theta n-P S}^{i},(\mathbf{b})$ deformation from center distance variation: $\delta_{d n-P S}^{i}$.

Under the ideal condition where the deformations of bearings and gear teeth are not considered, the movement of the $i$ th planet and the sun gear can be regarded as fixed-axis rotation. The angles fit a transmission ratio equation as follows:

$$
\left(\theta_{P}^{i}-\Delta \gamma_{P S}^{i}\right) \cdot Z_{P}+\left(\theta_{S}-\Delta \gamma_{P S}^{i}\right) \cdot Z_{S}=0
$$

where $\gamma_{P S}^{i}=\arctan \left[\left(y_{P}^{i}-y_{S}\right) /\left(x_{P}^{i}-x_{S}\right)\right]$ is the time-varying position angle between the center connection line $O_{P}^{i} O_{S}$ and $X$ axis, $\Delta \gamma_{P S}^{i}=\gamma_{P S}^{i}-\gamma_{P S 0^{\prime}}^{i}$, and $Z$ denotes the tooth number.

However, when considering the flexibility of the gear body, the deflection of gear teeth and the deformation of gear contact, the preceding equation does not fit anymore. The ideal angle $\theta_{P-P S}^{\prime i}$ of the planet gear under the condition of a rotation angle $\theta_{S}$ and a position angle $\Delta \gamma_{P S}^{i}$ is

$$
\theta_{P-P S}^{\prime i}=-\left(\theta_{S}-\Delta \gamma_{P S}^{i}\right) \cdot Z_{S} / Z_{P}+\Delta \gamma_{P S}^{i}
$$

As a result, the angle difference $\Delta \theta_{P-P S}^{i}$ with respect to the $i$ th planet gear is

$$
\Delta \theta_{P-P S}^{i}=\theta_{P}^{i}-\theta_{P-P S}^{\prime i}
$$

The linear deformation caused by this angle difference is

$$
\delta_{\theta n-P S}^{i}=r_{P-P S}^{i} \cdot \tan \Delta \theta_{P-P S}^{i} \cdot \cos \alpha_{P S}^{i}
$$

where $r_{P-P S}^{i}=d_{P S}^{i} \cdot Z_{P} /\left(Z_{S}+Z_{P}\right)$ is the pitch radius of the $i$ th planet gear, which is time-varying during the meshing process and can be derived from the center distance $d_{P S}^{i}=\left[\left(x_{P}^{i}-x_{S}\right)^{2}+\left(y_{P}^{i}-y_{S}\right)^{2}\right]^{1 / 2}$, and $\alpha_{P S}^{i}$ in the equation is the engagement angle: $\alpha_{P S}^{i}=\arccos \left[\left(r_{P b}+r_{S b}\right) / d_{P S}^{i}\right]$.

As shown in Figure $3 b, \Delta d_{P S}^{i}=d_{P S}^{i}-d_{P S 0}^{i}$, which denotes the center distance variation of $d_{P S}^{i}$, is another crucial factor in calculating the composite deformation. The linear deformation caused by the variation of center distance is

$$
\delta_{d n-P S}^{i}=-\Delta d_{P S}^{i} \cdot \sin \alpha_{P S}^{i}
$$

The normal composite deformation of the equivalent spring damper between the planet and sun gears is therefore given by

$$
\delta_{n-P S}^{i}=\delta_{\theta n-P S}^{i}+\delta_{d n-P S}^{i}=r_{P-P S}^{i} \cdot \tan \Delta \theta_{P-P S}^{i} \cdot \cos \alpha_{P S}^{i}-\Delta d_{P S}^{i} \cdot \sin \alpha_{P S}^{i} .
$$


The tangent composite deformation that is mainly caused by variation in center distance can be represented as

$$
\delta_{t-P S}^{i}=-\Delta d_{P S}^{i} \cdot \cos \alpha_{P S}^{i} .
$$

Furthermore, during the gear meshing process, the stiffness of an equivalent spring damper varies with changes in the gear meshing pair number, which toggles between 1 and 2 for a spur gear and is larger for a helical gear. According to the parameter identification of gear meshing stiffness, the relationship between the single pair and double pair gear meshing stiffness can be represented by a coefficient $\xi$ (generally $1<\xi<2$ ). Starting from the moment that a single meshing begins, the time-varying meshing stiffness in one cycle is

$$
k_{P S}= \begin{cases}k & 0 \leq \theta \leq(2-\varepsilon) \theta_{T} \\ \xi k & (2-\varepsilon) \theta_{T}<\theta \leq \theta_{T}\end{cases}
$$

where $\theta$ is the meshing phase angle, and $\theta_{T}$ is the cycle phase angle.

In addition, exchanges between the single and double pair of different planet-sun gear pairs are asynchronous during the process of loading sharing. Thus, the initial phase angles $\varphi_{i}$ representing the meshing state are introduced. Supposing that the total number of planets is $n$, and under the premise that design, manufacturing and assembly errors are ignored, the initial phase angle of an $i$ th planet gear that is different from the adjacent one is

$$
\varphi_{i}=(n-1) \varphi_{S 0} \& \varphi_{S 0}=\left[\frac{Z_{S}}{n}-\operatorname{int}\left(\frac{Z_{S}}{n}\right)\right] \cdot \frac{2 \pi}{Z_{S}} .
$$

Thus, the time-varying meshing stiffness of the $i$ th planet-sun gear meshing pair is

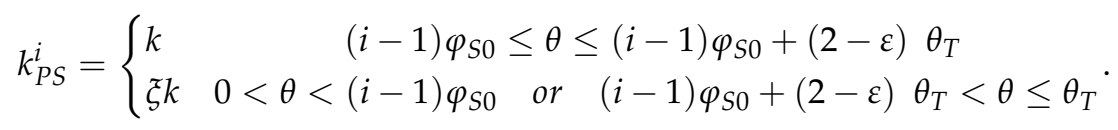

Based on the above derivations of the time-varying stiffness and composite deformations in the normal and tangent directions, the normal force exerted on the $i$ th planet gear by the sun gear in Figure 2 is calculated as

$$
\begin{aligned}
& N_{S P}^{i}=k_{P S}^{i} \cdot \delta_{n-P S}^{i} \\
& =k_{P S}^{i} \cdot\left[\frac{Z_{P}\left(r_{P b}+r_{S b}\right)}{Z_{S}+Z_{P}} \tan \left(\theta_{P}^{i}+\frac{Z_{S}}{Z_{P}} \theta_{S}^{i}-\frac{Z_{S}+Z_{P}}{Z_{P}} \Delta \gamma_{P S}^{i}\right)-\left(d_{P S}^{i}-d_{P S 0}^{i}\right) \cdot \sin \alpha_{P S}^{i}\right] .
\end{aligned}
$$

The direction of this force is tangent to the base circle of the planet gear. The angle between it and the $\mathrm{X}$ axis is

$$
\beta_{S P-N}^{i}=\pi / 2+\gamma_{S P}^{i}-\alpha_{P S}^{i} .
$$

The tangent friction force between the planet and sun gear is composed of the viscous damping and coulomb friction forces:

$$
f_{S P}^{i}=\left(\mu_{P S} N_{S P}^{i}+c_{P S} \cdot \dot{\delta}_{t-P S}^{i}\right) \cdot \operatorname{sgn}\left(\dot{\delta}_{t-P S}^{i}\right) .
$$

In this equation, $\mu_{P S}$ is the coulomb friction coefficient, $c_{P S}$ is the viscous damping coefficient, and sgn $(x)$ is the sign function.

The tangent friction force is perpendicular to the normal force, direction of which is opposite to the direction of the relative sliding velocity. The angle between it and the $X$ axis is

$$
\beta_{S P-f}^{i}=\gamma_{S P}^{i}-\alpha_{P S}^{i} .
$$




\subsubsection{Force Derivation of the Engagement of the Ring and $i$ th Planet Gear}

Analysis procedures to derive the force between the ring and $i$ th planet gears are similar to the analysis procedures for that between the sun and $i$ th planet gears. The difference is mainly concentrated in a small fluctuation in meshing stiffness between the ring and planet gear due to the high contact ratio, such that meshing stiffness can be regarded as a constant in some situations, which will be proved via parameter identification results in a later section.

The center distance of the $i$ th planet and ring gear is

$$
d_{P R}^{i}=\sqrt{\left(x_{P}^{i}-x_{R}\right)^{2}+\left(y_{P}^{i}-y_{R}\right)^{2}} .
$$

The time-varying position angle between the center connection line and the $\mathrm{X}$ axis is

$$
\gamma_{P R}^{i}=\arctan \left[\left(y_{P}^{i}-y_{R}\right) /\left(x_{P}^{i}-x_{R}\right)\right] \& \Delta \gamma_{P R}^{i}=\gamma_{P R}^{i}-\gamma_{P R 0}^{i} .
$$

Under the ideal condition, the rotational angles fit a transmission ratio equation as follows:

$$
\left(\theta_{P}^{i}-\Delta \gamma_{P R}^{i}\right) \cdot Z_{P}-\left(\theta_{R}-\Delta \gamma_{P R}^{i}\right) \cdot Z_{R}=0 .
$$

The ideal angle $\theta_{P-P R}^{\prime i}$ of a planet gear under the condition of rotation angle of $\theta_{R}$ and $\Delta \gamma_{P R}^{i}$ is

$$
\theta_{P-P R}^{i}=\left(\theta_{R}-\Delta \gamma_{P R}^{i}\right) \cdot Z_{R} / Z_{P}+\Delta \gamma_{P R}^{i} .
$$

As a result, the angle difference $\Delta \theta_{P-P R}^{i}$ with respect to the $i$ th planet gear is

$$
\Delta \theta_{P-P R}^{i}=\theta_{P}^{i}-\theta_{P-P R}^{i} .
$$

The linear deformation caused by the angle difference is

$$
\delta_{\theta n-P R}^{i}=-r_{P-P R}^{i} \cdot \tan \Delta \theta_{P-P R}^{i} \cdot \cos \alpha_{P R}^{i}
$$

where $\alpha_{P R}^{i}$ is the engagement angle and $r_{P-P R}^{i}$ is the time-varying pitch radius of the $i$ th planet gear, which can be derived from the center distance $d_{P R}^{i}, r_{P-P R}^{i}=d_{P R}^{i} \cdot Z_{P} /\left(Z_{R}-Z_{P}\right)$.

The linear deformation caused by the variation in center distance is

$$
\delta_{d n-P R}^{i}=\Delta d_{P R}^{i} \cdot \sin \alpha_{P R}^{i} .
$$

Thus, the equivalent normal composite deformation of the spring damper between the ring and $i$ th planet gears is

$$
\delta_{n-P R}^{i}=\delta_{\theta n-P R}^{i}+\delta_{d n-P R}^{i}=-r_{P-P R}^{i} \cdot \tan \Delta \theta_{P-P R}^{i} \cdot \cos \alpha_{P R}^{i}+\Delta d_{P R}^{i} \cdot \sin \alpha_{P R}^{i} .
$$

As in the previous section, the tangent deformation mainly caused by variation in center distance between the ring and planet gear is

$$
\delta_{t-P R}^{i}=-\Delta d_{P R}^{i} \cdot \cos \alpha_{P R}^{i} .
$$

$k_{P R}$ denotes the equivalent meshing stiffness of the ring and planet gears, and the fluctuation its value can be ignored. Based on the previous derivation of the deformation, the normal force on the $i$ th planet gear can be computed as

$$
\begin{aligned}
& N_{R P}^{i}=k_{P R} \cdot \delta_{n-P R}^{i} \\
& =k_{P R} \cdot\left[-\frac{Z_{P}\left(r_{R b}-r_{P b}\right)}{Z_{R}-Z_{P}} \tan \left(\theta_{P}^{i}-\frac{Z_{R}}{Z_{P}} \theta_{R}^{i}+\frac{Z_{R}-Z_{P}}{Z_{P}} \Delta \gamma_{P R}^{i}\right)+\left(d_{P R}^{i}-d_{P R 0}^{i}\right) \cdot \sin \alpha_{P R}^{i}\right],
\end{aligned}
$$


Its direction is tangent to the base circle of the $i$ th planet gear, and the angle between it and the $\mathrm{X}$ axis is

$$
\beta_{R P-N}^{i}=\pi / 2+\gamma_{P R}^{i}+\alpha_{P R}^{i} .
$$

The tangent friction force $f_{R P}^{i}$ between the $i$ th planet gear and ring gear is composed of the viscous damping and coulomb friction forces:

$$
f_{R P}^{i}=\left(\mu_{P R} N_{R P}^{i}+c_{P R} \cdot \dot{\delta}_{t-P R}^{i}\right) \cdot \operatorname{sgn}\left(\dot{\delta}_{t-P R}^{i}\right),
$$

in which the definitions of $\mu_{P R}, c_{P R}$ and the function $\operatorname{sgn}(x)$ are almost the same as in the previous subsection.

The tangent friction force is perpendicular to the normal force, direction of which is opposite to the direction of relative sliding velocity. The angle between it and the $\mathrm{X}$ axis is

$$
\beta_{R P-f}^{i}=\pi+\gamma_{P R}^{i}+\alpha_{P R}^{i} .
$$

\subsubsection{Bearing Force Analysis between Carrier and $i$ th Planet Gear}

The interaction between the carrier and the planet gear can be represented using an equivalent spring damper force and a friction torque. $R_{P}$ denotes the distribution radius of the planets, and $\gamma_{C P 0}^{i}$ is the initial distribution angle, namely the angle between the center line of the $i$ th planet and the carrier along the $X$ axis. As such, the deformation of the $i$ th planet relative to the carrier is

$$
\delta_{C P-x}^{i}=x_{P}^{i}-\left[x_{C}+R_{P} \cdot \cos \left(\theta_{C}+\gamma_{C P 0}^{i}\right)\right] \& \delta_{C P-y}^{i}=y_{P}^{i}-\left[y_{C}+R_{P} \cdot \cos \left(\theta_{C}+\gamma_{C P 0}^{i}\right)\right] .
$$

The rotational angle of the $i$ th planet relative to the carrier is $\delta_{C P-\theta}^{i}=\theta_{P}^{i}-\theta_{C}$. Therefore, the reaction force and torque on the center of the $i$ th planet are computed as follows:

$$
\begin{aligned}
& F_{C P-x}^{i}=-k_{C P B} \cdot \delta_{C P-x}^{i} \\
& F_{C P-y}^{i}=-k_{C P B} \cdot \delta_{C P-y}^{i} \\
& T_{C P-z}^{i}=-\left(\mu_{C P B} \sqrt{F_{C P-x}^{i}+F_{C P-y}^{i}} \cdot d_{C P B} / 2+c_{C P B} \cdot \dot{\delta}_{C P-\theta}^{i}\right) \cdot \operatorname{sgn}\left(\dot{\delta}_{C P-\theta}^{i}\right)
\end{aligned},
$$

where $k_{C P B}$ is the bearing stiffness, $d_{C P B}$ is the nominal diameter of bearings, $\mu_{C P B}$ is the coulomb friction coefficient, and $c_{C P B}$ is the viscous damping coefficient.

\subsubsection{System Dynamic Equations}

To construct the sun gear dynamic equations, supposing that $k_{S B}$ and $c_{S B}$ are the bearing stiffness and the rotational viscous damping coefficient of the sun gear bearing if it exists, respectively, and that there exist $n$ planet gears:

$$
\begin{aligned}
& M_{S} \ddot{x}_{S}+k_{S B} x_{S}-\sum_{i=1}^{n}\left(N_{P S-x}^{i}+f_{P S-x}^{i}\right)=F_{S x} \\
& M_{S} \ddot{y}_{S}+k_{S B} y_{S}-\sum_{i=1}^{n}\left(N_{P S-y}^{i}+f_{P S-y}^{i}\right)=F_{S y}+G_{S} . \\
& I_{S} \ddot{\theta}_{S}+c_{S B} \dot{\theta}_{S}-\sum_{i=1}^{n}\left(T_{P S-N}^{i}+T_{P S-f}^{i}\right)=T_{S}
\end{aligned}
$$

$F_{x}, F_{y}$ and $T$ in Equations (31)-(38) are the external forces and torque respectively, values of which are considered zeroes if they do not exist. Substituting the specific formulas of $N_{P S}^{i}, f_{P S}^{i}$ and $T_{P S}^{i}$, the sun gear dynamic equations can be rewritten as

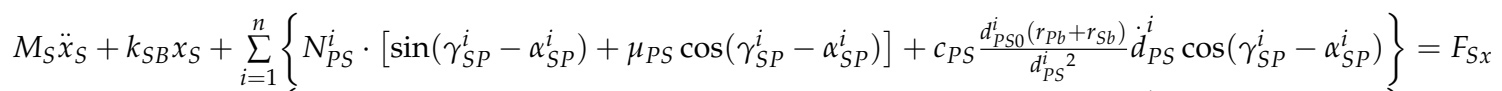

$$
\begin{aligned}
& M_{S} \ddot{y}_{S}+k_{S B} y_{S}+\sum_{i=1}^{n}\left\{N_{P S}^{i} \cdot\left[\cos \left(\gamma_{S P}^{i}-\alpha_{S P}^{i}\right)+\mu_{P S} \sin \left(\alpha_{S P}^{i}-\gamma_{S P}^{i}\right)\right]+c_{P S} \frac{d_{P S}^{i}\left(r_{P b}+r_{S b}\right)}{d_{P S}^{i}{ }^{2}} \dot{d}_{P S}^{i} \cos \left(\alpha_{S P}^{i}-\gamma_{S P}^{i}\right)\right\}=F_{S y} . \\
& I_{S} \ddot{\theta}_{S}+c_{S B} \dot{\theta}_{S}+\sum_{i=1}^{n}\left\{N_{P S}^{i} \cdot\left[r_{S b}-\mu_{P S} \frac{Z_{S}}{Z_{S}+Z_{P}} d_{P S}^{i} \sin \alpha_{P S}^{i}\right]-c_{P S} \frac{Z_{S} d_{P S 0}\left(r_{P b}+r_{S b}\right)}{\left(Z_{S}+Z_{P}\right) d_{P S}^{i}} \sin \alpha_{P S}^{i} \cdot d_{P S}^{i}\right\}=T_{S}
\end{aligned}
$$


For the ring gear, the dynamic equations derivation process is similar. $k_{R B}$ and $c_{R B}$ are assumed to be the ring bearing stiffness and the rotational viscous damping coefficient if they exist, respectively.

$$
\begin{aligned}
& M_{R} \ddot{x}_{R}+k_{R B} x_{R}-\sum_{i=1}^{n}\left(N_{P R-x}^{i}+f_{P R-x}^{i}\right)=F_{R x} \\
& M_{R} \ddot{y}_{R}+k_{R B} y_{R}-\sum_{i=1}^{n}\left(N_{P R-y}^{i}+f_{P R-y}^{i}\right)=F_{R y}+G_{R} . \\
& I_{R} \ddot{\theta}_{R}+c_{R B} \dot{\theta}_{R}-\sum_{i=1}^{n}\left(T_{P R-N}^{i}+T_{P R-f}^{i}\right)=T_{R}
\end{aligned}
$$

Plugging in the corresponding terms, the equations can be rewritten as

$$
\begin{aligned}
& M_{R} \ddot{x}_{R}+k_{R B} x_{R}+\sum_{i=1}^{n}\left\{N_{P R}^{i} \times\left[\sin \left(\gamma_{R P}^{i}+\alpha_{R P}^{i}\right)+\mu_{P R} \cos \left(\gamma_{R P}^{i}+\alpha_{R P}^{i}\right)\right]+c_{P R} \frac{d_{P R O}^{i}\left(r_{P b}+r_{R b}\right)}{\left.d_{P R}^{i}\right)^{2}} \dot{d}_{P R}^{i} \cos \left(\gamma_{R P}^{i}+\alpha_{R P}^{i}\right)\right\}=F_{R x} \\
& M_{R} \ddot{y}_{R}+k_{R B} y_{R}+\sum_{i=1}^{n}\left\{N_{P R}^{i} \times\left[\cos \left(\gamma_{R P}^{i}+\alpha_{R P}^{i}\right)+\mu_{P R} \sin \left(\alpha_{R P}^{i}+\gamma_{R P}^{i}\right)\right]+c_{P R} \frac{d_{P R O}^{i}\left(r_{P b}+r_{R b}\right)}{d_{P R}^{i}{ }^{2}} \dot{d}_{P R}^{i} \cos \left(\alpha_{R P}^{i}-\gamma_{R P}^{i}\right)\right\}=F_{R y}+G_{R} . \\
& I_{R} \ddot{\theta}_{R}+c_{S B} \dot{\theta}_{S}+\sum_{i=1}^{n}\left\{N_{P R}^{i} \times\left[r_{R b}+\mu_{P R} \frac{Z_{R}}{Z_{R}+Z_{P}} d_{P R}^{i} \sin \alpha_{P R}^{i}\right]-c_{P R} \frac{Z_{R} d_{P R O}\left(r_{P b}+r_{R b}\right)}{\left(Z_{R}+Z_{P}\right) d_{P R}^{i}} \sin \alpha_{P R}^{i} \times d_{P R}^{i}\right\}=T_{R}
\end{aligned}
$$

For the $i$ th planet gear, as the applied forces on it include the engaging forces from the ring and sun gear and the bearing force, its dynamic equations are given by

$$
\begin{aligned}
& M_{P} \ddot{x}_{P}^{i}+k_{C P B} \cdot\left[x_{P}^{i}-x_{C}-R_{P} \cdot \cos \left(\theta_{C}+\gamma_{C P 0}^{i}\right)\right] \\
& -N_{P S}^{i} \cdot\left[\sin \left(\gamma_{S P}^{i}-\alpha_{S P}^{i}\right)+\mu_{P S} \cos \left(\gamma_{S P}^{i}-\alpha_{S P}^{i}\right)\right]-c_{P S} \frac{d_{P S 0}^{i}\left(r_{P b}+r_{S b}\right)}{\left.d_{P S}^{i}\right)^{i}} \dot{d}_{P S} \cos \left(\gamma_{S P}^{i}-\alpha_{S P}^{i}\right) \\
& -N_{P R}^{i} \cdot\left[\sin \left(\gamma_{R P}^{i}+\alpha_{R P}^{i}\right)+\mu_{P R} \cos \left(\gamma_{R P}^{i}+\alpha_{R P}^{i}\right)\right]-c_{P R} \frac{d_{P R 0}^{i}\left(r_{P b}+r_{R b}\right)}{d_{P R}^{i}} \dot{d}_{P R}^{i} \cos \left(\gamma_{R P}^{i}+\alpha_{R P}^{i}\right)=0 \\
& M_{P} \ddot{y}_{P}^{i}+k_{C P B} \cdot\left[y_{P}^{i}-y_{C}-R_{P} \cdot \sin \left(\theta_{C}+\gamma_{C P 0}^{i}\right)\right] \\
& -N_{P S}^{i} \cdot\left[\cos \left(\gamma_{S P}^{i}-\alpha_{S P}^{i}\right)+\mu_{P S} \sin \left(\alpha_{S P}^{i}-\gamma_{S P}^{i}\right)\right]-c_{P S} \frac{d_{P S O}^{i}\left(r_{P b}+r_{S b}\right)}{d_{P S}^{i} \dot{d}_{P S}^{i} \cos \left(\alpha_{S P}^{i}-\gamma_{S P}^{i}\right)} \\
& -N_{P R}^{i} \cdot\left[\cos \left(\gamma_{R P}^{i}+\alpha_{R P}^{i}\right)+\mu_{P R} \sin \left(\alpha_{R P}^{i}+\gamma_{R P}^{i}\right)\right]+c_{P R} \frac{d_{P R 0}^{i}\left(r_{P b}+r_{R b}\right)}{d_{P R}^{i}{ }^{2}} \dot{d}_{P R}^{i} \cos \left(\alpha_{R P}^{i}-\gamma_{R P}^{i}\right)=G_{P}{ }^{i} \\
& I_{P}^{i} \ddot{\theta}_{P}^{i}+c_{P B}\left(\dot{\theta}_{P}^{i}-\dot{\theta}_{R}\right)-N_{P S}^{i} \cdot\left[r_{S b}-\mu_{P S} \frac{Z_{S}}{Z_{S}+Z_{P}} d_{P S}^{i} \sin \alpha_{P S}^{i}\right]+c_{P S} \frac{Z_{S} d_{P S 0}\left(r_{P b}+r_{S b}\right)}{\left(Z_{S}+Z_{P}\right) d_{P S}^{i}} \sin \alpha_{P S}^{i} \cdot d_{P S}^{i}, \\
& -N_{P R}^{i} \cdot\left[r_{R b}+\mu_{P R} \frac{Z_{R}}{Z_{R}+Z_{P}} d_{P R}^{i} \sin \alpha_{P R}^{i}\right]+c_{P R} \frac{Z_{R} d_{P R 0}\left(r_{P b}+r_{R b}\right)}{\left(Z_{R}+Z_{P}\right) d_{P R}^{i}} \sin \alpha_{P R}^{i} \cdot d_{P R}^{i}=0
\end{aligned}
$$

For the planet carrier, similarly, dynamic equations can be expressed as

$$
\begin{aligned}
& M_{C} \ddot{x}_{C}-k_{C P B} \cdot \sum_{i=1}^{n}\left[x_{P}^{i}-x_{C}-R_{P} \cdot \cos \left(\theta_{C}+\gamma_{C P 0}^{i}\right)\right]=F_{C x} \\
& M_{C} \ddot{y}_{C}-k_{C P B} \cdot \sum_{i=1}^{n}\left[y_{P}^{i}-y_{C}-R_{P} \cdot \sin \left(\theta_{C}+\gamma_{C P 0}^{i}\right)\right]=F_{C y}+G_{P} \\
& I_{c} \ddot{\theta}_{C}+c_{p b}\left(\dot{\theta}_{r}-{ }^{i} \dot{\theta}_{p}\right)+k_{C P B} \cdot \sum_{i=1}^{n}\left[x_{P}^{i}-x_{C}-R_{P} \cdot \cos \left(\theta_{C}+\gamma_{C P 0}^{i}\right) \cdot\left(x_{P}^{i}-x_{C}\right)\right] \\
& -k_{C P B} \cdot \sum_{i=1}^{n}\left[y_{P}^{i}-y_{C}-R_{P} \cdot \sin \left(\theta_{C}+\gamma_{C P 0}^{i}\right) \cdot\left(y_{P}^{i}-y_{C}\right)\right]=T_{C}
\end{aligned} .
$$

\section{Dynamic Modeling of a WTG Test Rig}

A full test rig which was used to test and evaluate the dynamic performance of a 2 MW WTG is introduced in this section. A LTC model considering specific structures of this WTG was constructed using the proposed modeling approach of a planetary gear set with floating components.

\subsection{Structure of the Full Test Rig}

The 2 MW WTG modeled is depicted in Figure 4. It primarily consists of three gear sets: a low-speed planetary gear set (LSP), a high-speed planetary gear set (HSP) and a 
parallel-shaft helical gear set (PSH). To reach the design objective of power dividing, the LSP had four transverse fixed planet gears and a floating sun gear, while the HSP had a fixed ring gear and a floating carrier with three planet gears affixed with bearings. The wind field excitation acted on the ring gear of the LSP, and the grid load from the electric generator acted on the output axis of the PSH. The intricate dynamics of the entire floating component, including the sun gear from the LSP, the carrier and three planet gears from the HSP, made this WTG quite distinct from common designed ones.

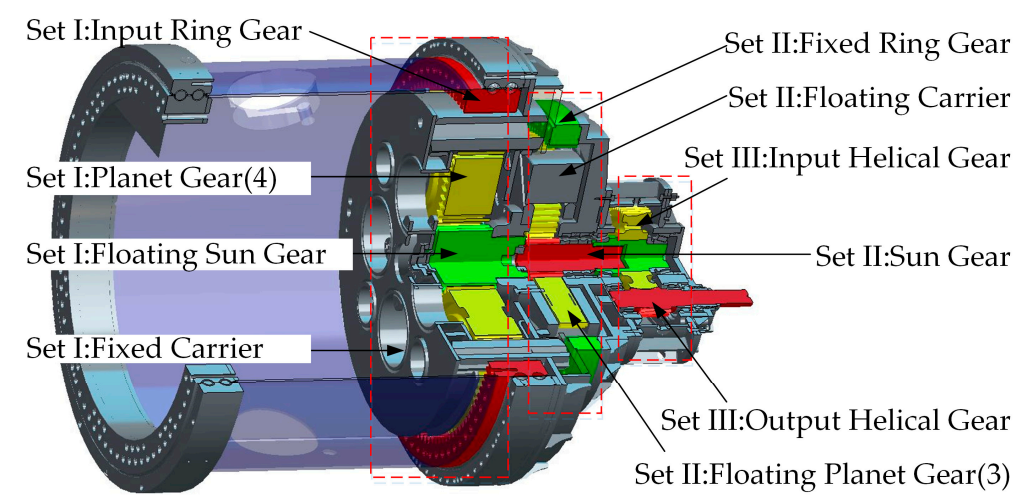

Figure 4. 3D drivetrain model of the 2 MW WTG.

Figure 5 shows the 3D geometry model of the entire test rig. Part 1 is a loading motor, the speed of which was controlled, and part 2 is an auxiliary reduction gearbox. A combination of the two was utilized to imitate the wind input. Part 5 is a loading generator, the torque of which was controlled. Part 4 is the tested 2 MW WTG, which is connected with Part 2 through a universal coupling and with Part 5 through a flexible flange.

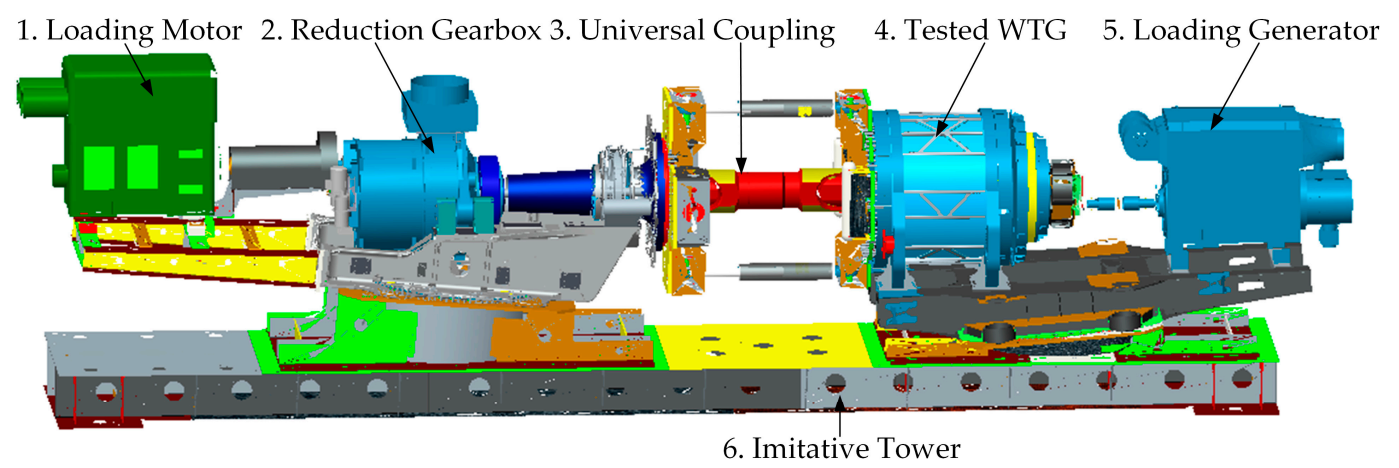

Figure 5. 3D model of the entire test rig.

\subsection{Dynamic Model of the Full Test Rig}

A LTC model of the full test rig was constructed based on the proposed method in order to analyze the dynamic loading factors and dynamic behavior.

Figure 6 shows the schematic of the simplified LTC dynamic model of the full test rig. Not only the meshing effect but also the bearing flexibility and torsional elasticity of shafts and joints were considered. In the model, the gear meshing effects of the LSG and HSG gear sets were considered using the proposed method. The PSH was regarded as a spur gear set with high contact ratio under the condition that axial flexibility was not considered. The imitated wind input that combined a loading motor and a reduction gearbox was considered an excitation with rotational inertia, and the output generator was considered a torque loading with rotational inertia. In addition, torsional models of the spline connection, the universal coupling and the flange joint were built, and the radial stiffness of different bearings was included. 


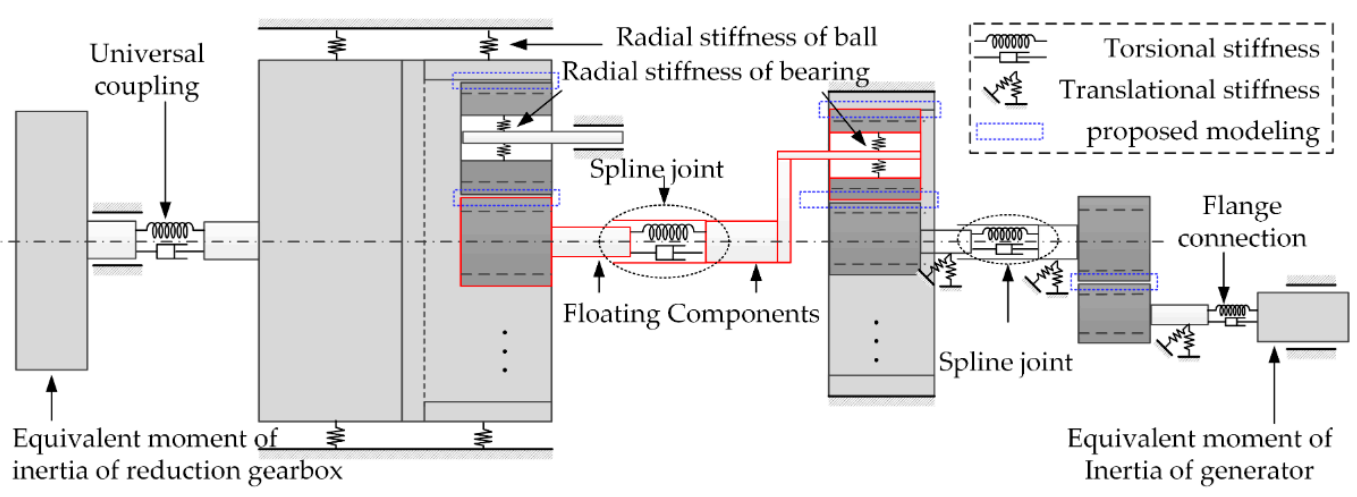

Figure 6. The LTC dynamic model of the entire test rig.

This proposed LTC model in Figure 6 was implemented with the aid of the MS. ADAMS software due to its superiority in calculation of multibody systems. In the simulated model, translational displacements and rotational angles of all components were acquired in real time. The time-varying deformations and relative velocities of the elastic elements in Figure 6 were calculated using the derived equations. The meshing forces of gears, torques of shafts, bearing forces, etc. were then also computed using the equations in Section 2, and finally acted on the corresponding components using the force function of ADAMS. It should also be noted that parameters like meshing stiffness were also time-varying according to the related switching conditions derived in Section 2.

\subsection{Parameter Identification of the Dynamic Model}

Tables 2 and 3 show the main design parameters of the LSP, HSP and PSH gear sets, based on which basic parameters of gears and gear pairs could be derived and calculated.

Table 2. Design parameters of the planetary gear sets.

\begin{tabular}{cccccc}
\hline Items & $\begin{array}{c}\text { Ring } \\
\text { Tooth Number }\end{array}$ & $\begin{array}{c}\text { Planet } \\
\text { Tooth Number }\end{array}$ & $\begin{array}{c}\text { Sun } \\
\text { Tooth Number }\end{array}$ & Module & $\begin{array}{c}\text { Tooth } \\
\text { Profile Angle }\end{array}$ \\
\hline LSP & 118 & 48 & 22 & 16 & $20^{\circ}$ \\
HSP & 118 & 50 & 17 & 12 & $20^{\circ}$ \\
\hline
\end{tabular}

Table 3. Design parameters of the helical gear set.

\begin{tabular}{cccccc}
\hline Item & $\begin{array}{c}\text { Input } \\
\text { Tooth Number }\end{array}$ & $\begin{array}{c}\text { Output } \\
\text { Tooth Number }\end{array}$ & Helical Angle & Module & $\begin{array}{c}\text { Tooth } \\
\text { Profile Angle }\end{array}$ \\
\hline PSH & 59 & 21 & $8^{\circ}$ & 9 & $20^{\circ}$ \\
\hline
\end{tabular}

As shown in Figure 7, parameter identifications of the gear meshings, the connections and the shafts were conducted by means of Finite Element Analysis (FEA). In the process, the loading was increased gradually until reaching the service load, and the stiffness value was calculated as the slope of the nonlinear force-displacement curve on the operating point. For gear meshing, both the single and double pair contact situations were calculated. Detailed identification results are shown in Tables 3-5.

Parameter identification of the radial bearing stiffness was conducted in a similar way. The inner or outer ring was fixed while the other one was loaded until reaching the service load, and the bearing stiffness was calculated through the nonlinear relationship between loading force and relative radial displacement. Table 6 shows the identification results. With these identified parameters, dynamic behavior of the 2 MW WTG could be simulated. 

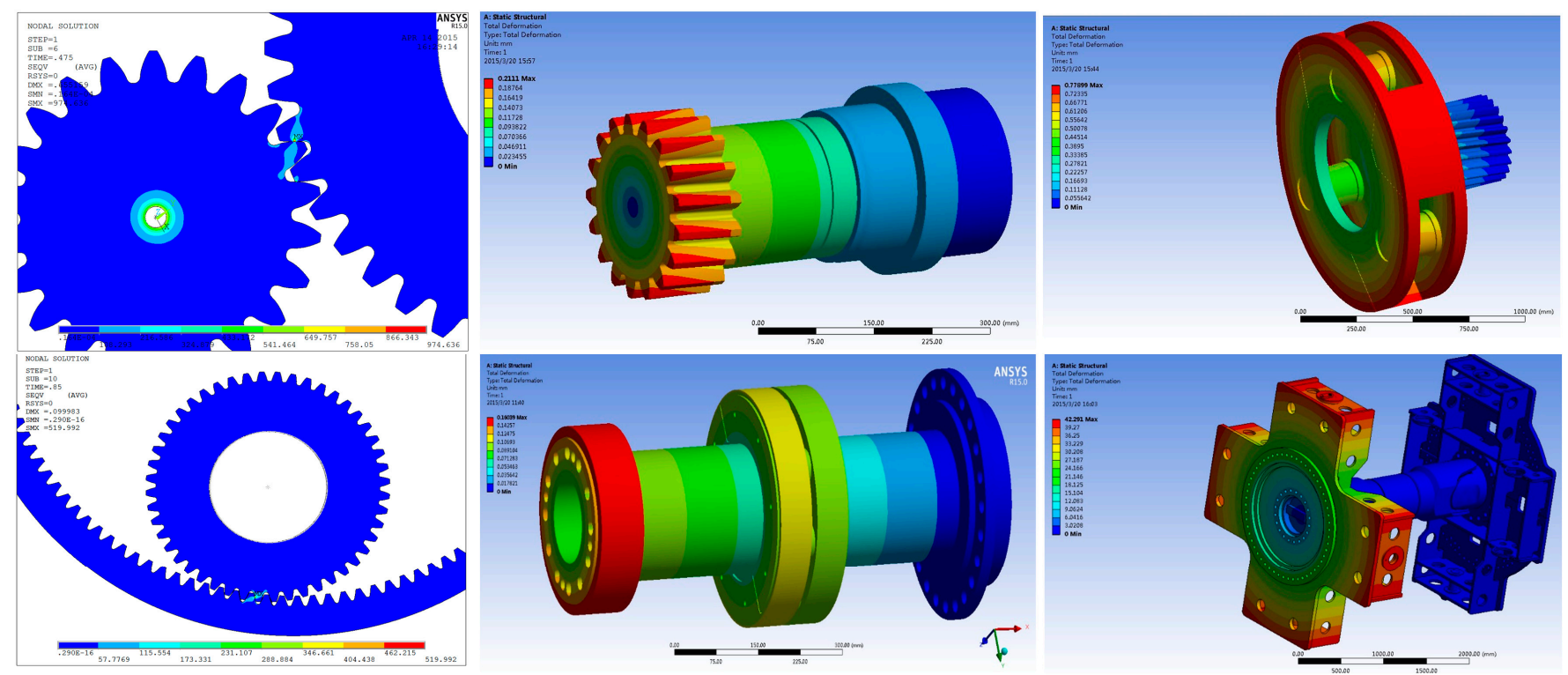

Figure 7. Parameter identification of gear meshings, connections and shafts by means of FEA.

Table 4. Parameter identification results of the gear meshings.

\begin{tabular}{ccccc}
\hline \multirow{2}{*}{ Position } & $\begin{array}{c}\text { Service Load } \\
\left(\times \mathbf{1 0}^{\mathbf{5}} \mathbf{N}\right)\end{array}$ & \multicolumn{2}{c}{$\begin{array}{c}\text { Torsional Stiffness } \\
\left(\times \mathbf{1 0}^{\mathbf{8}} \mathbf{N} \cdot \mathbf{m} / \mathbf{r a d}\right)\end{array}$} & \multirow{2}{*}{$\begin{array}{c}\text { Variable } \\
\text { Stiffness }\end{array}$} \\
\cline { 3 - 4 } & & Single Pair & Double Pair & \\
Coefficient
\end{tabular}

Table 5. Parameter identification results of the connections and shafts.

\begin{tabular}{ccc}
\hline Position & $\begin{array}{c}\text { Service Load } \\
\left(\times \mathbf{1 0}^{\mathbf{4}} \mathbf{N} \cdot \mathbf{m}\right)\end{array}$ & $\begin{array}{c}\text { Torsional Stiffness } \\
\left(\times \mathbf{1 0}^{\mathbf{8}} \mathbf{N} \cdot \mathbf{m} / \mathbf{r a d}\right)\end{array}$ \\
\hline Wind input-input shaft & 127 & 0.49 \\
LSP sun-HSP carrier & 23.9 & 1.81 \\
HSP sun-PSH input & 2.99 & 0.17 \\
PSH output-output shaft & 1.06 & 0.055 \\
Output shaft-generator & 1.06 & 0.45 \\
\hline
\end{tabular}

Table 6. Parameter identification results of the bearings.

\begin{tabular}{ccc}
\hline Bearing Position & $\begin{array}{c}\text { Service Load } \\
\left(\times \mathbf{1 0}^{\mathbf{5}} \mathbf{N}\right)\end{array}$ & $\begin{array}{c}\text { Bearing Stiffness } \\
\left(\times \mathbf{1 0}^{\mathbf{9}} \mathbf{~ N} / \mathbf{m}\right)\end{array}$ \\
\hline LSP: planet bearing & 6.68 & 5.02 \\
HSP: planet bearing & 1.94 & 4.20 \\
HSP: sun bearing & 0.115 & 2.60 \\
PSH: input bearing 1 & 0.58 & 3.46 \\
PSH: input bearing 2 & 0.58 & 3.60 \\
PSH: output bearing 1 & 0.58 & 2.70 \\
PSH: output bearing 2 & 0.58 & 0.43 \\
\hline
\end{tabular}

\section{Experimental Validation and Dynamic Analysis of the WTG}

To demonstrate the validity of the novel proposed modeling method of heavyduty gearboxes, experiments were conducted on the 2 MW WTG test rig specified in 
Figures 4 and 5, and the experimental results were compared with the simulation results from the LTC model of the entire test rig under loading conditions identical to the rated working environment. Furthermore, dynamic loading factors of different gear sets, which are crucial to the design of WTG system, were calculated based on the LTC model that was verified by experiments.

\subsection{Configuration of the Full Test Rig}

The experiments were conducted in a workshop of SANY (a wind power equipment company). The test rig was loaded according to the rated working condition of the $2 \mathrm{MW}$ WTG: the rated rotating speed of the imitated wind input that combined the loading motor and the reduction gearbox was $15 \mathrm{rpm}$ and the rated loading torque from the generator, acting on the PSH output axis, was $1.06 \times 10^{4} \mathrm{~N} \cdot \mathrm{m}$. Single-axis vibration acceleration sensors (PCB 352C34) were utilized to measure the vibration behavior of the WTG system, and the detailed position arrangement of sensors is shown in Figure 8. The data acquisition bandwidth was set to be $8192 \mathrm{~Hz}$. Sensor signals were imported into a LMS SCADAS III data acquisition system, and the accompanying software LMS Test was employed for data processing and analysis. The simulation LTC dynamic model was loaded on the input equivalent moment of inertia progressively to a constant rotating speed of $15 \mathrm{rpm}$ and on the output equivalent moment of inertia with an identical torque, to make sure that the loading conditions of the simulation and experiment WTG were identical. The variable stiffness coefficients of the three gear sets in the simulation model were set to be 1.1, 1.4 and 1.05 , respectively, based on the identification results.

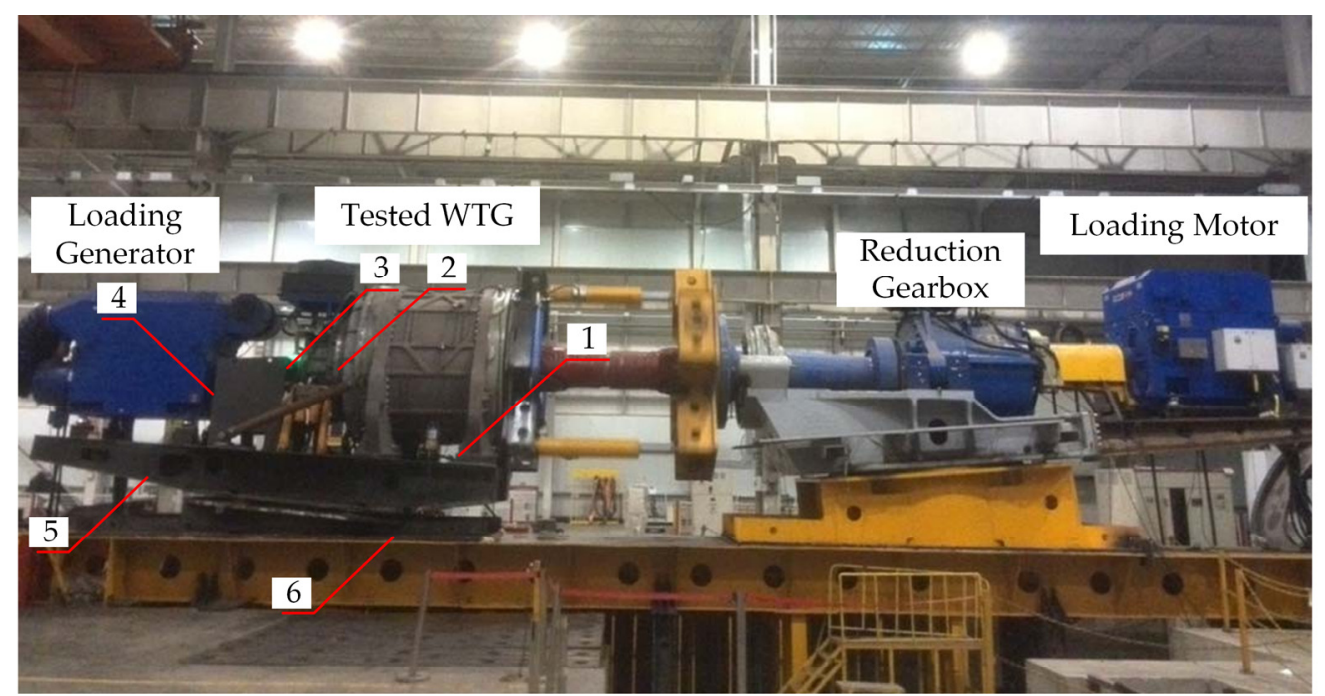

1- Front chassis 2- Stage2:ring-gear 3- Output shaft of gearbox 4-Input shaft of generator

5- Back chassis 6- Imitative tower

Figure 8. Full test rig and sensor arrangement.

\subsection{Comparison of the Simulated and Experimental Results}

Based on the identified parameters and loading conditions, theoretical meshing frequencies of the tested WTG were computed through multiplying the rotating frequency by the tooth number. The results are listed in Table 7, and were $29.5 \mathrm{~Hz}, 158.2 \mathrm{~Hz}$ and $628.3 \mathrm{~Hz}$, respectively. 
Table 7. Theoretical meshing frequencies at the rated rotating speed of $15 \mathrm{rpm}$.

\begin{tabular}{cccc}
\hline Position & $\begin{array}{c}\text { Rotating Speed } \\
(\mathbf{r} / \mathbf{m i n})\end{array}$ & Tooth Number & $\begin{array}{c}\text { Theoretical Meshing Frequency } \\
(\mathbf{H z})\end{array}$ \\
\hline LSP: ring & 15 & 118 & 29.5 \\
LSP: planet & 36.87 & 48 & 29.5 \\
LSP: sun & 80.45 & 22 & 29.5 \\
HSP: planet & 189.84 & 50 & 158.2 \\
HSP: sun & 638.82 & 17 & 158.2 \\
PSH: input & 638.82 & 59 & 628.3 \\
PSH: output & 1794.75 & 21 & 628.3 \\
\hline
\end{tabular}

Acceleration signals from the $\mathrm{X}$ and $\mathrm{Y}$ directions were synthesized to reveal the lateral vibration behavior of the full test rig. Figures 9 and 10 are the comparison diagrams for the front chassis and the output shaft respectively, and Table 8 shows the comparison of the main frequency components of the experimental and simulated results from different locations on the entire WTG system.
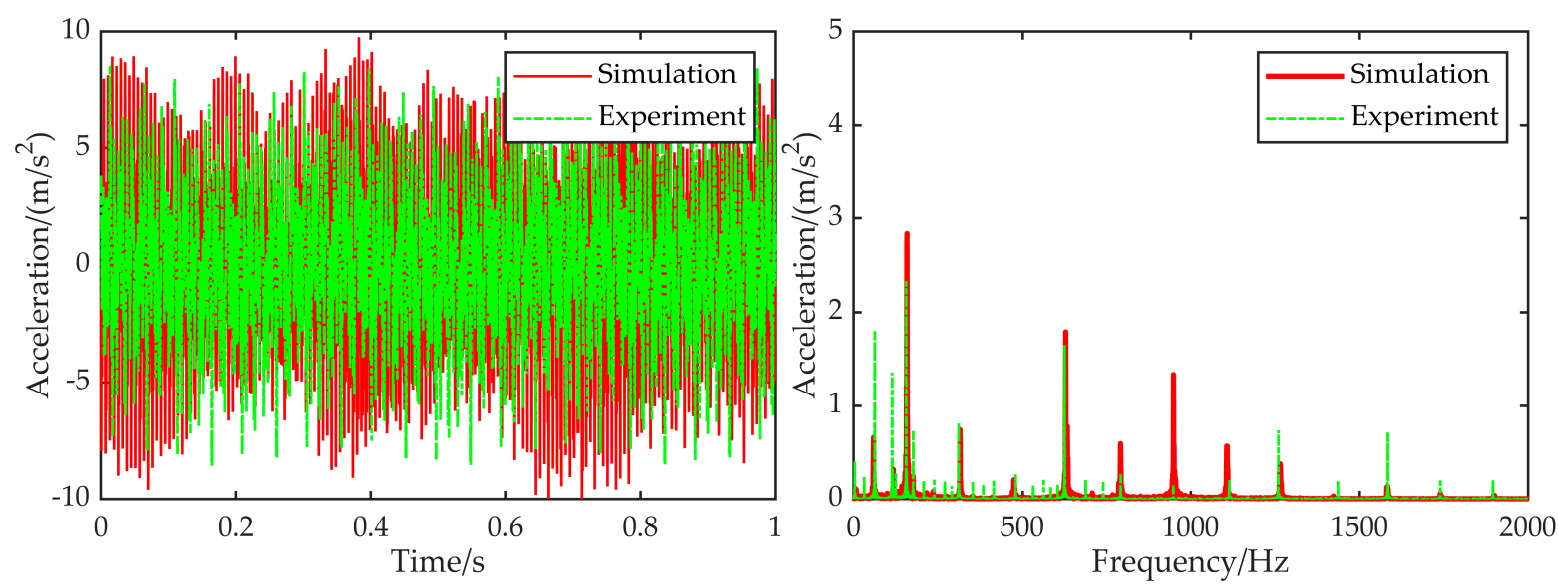

Figure 9. Comparison of the simulated and experimental results of the front chassis.
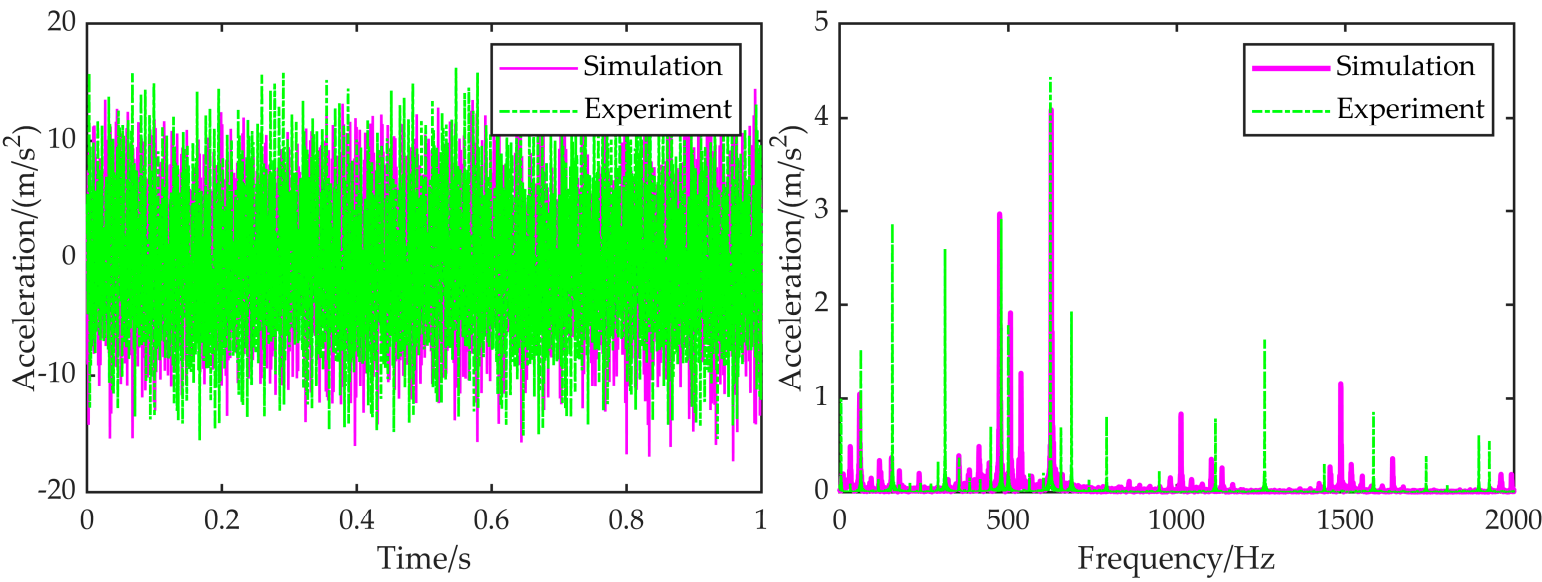

Figure 10. Comparison of the simulated and experimental results of the output shaft. 
Table 8. Eigen-frequencies comparison of the entire system.

\begin{tabular}{ccccc}
\hline Measured Position & $\begin{array}{c}\text { Measured Acceleration } \\
\text { Frequency } \mathbf{( H z )}\end{array}$ & Simulated Position & $\begin{array}{c}\text { Simulated Acceleration } \\
\text { Frequency (Hz) }\end{array}$ \\
\hline Front chassis & $62.5,114.4,156.3,312.5,625$ & & LSP: bearing & $59.2,158.7,316.2,628.1$ \\
\hline HSP:ring gear & $62.5,312.5,479.1,625$ & HSP: ring gear & $59.2,316.5,474.4,628$ \\
\hline Output shaft & $62.5,156.3,312.5,479.1,500.2,625$ & & PSH: input bearing \& HSP: \\
output bearing & $\begin{array}{c}29.5,158.7,316.2,413.2,474.4, \\
506.6,537.3,628.1\end{array}$ \\
\hline Input of generator & $62.5,312.5,416.6,479.1,541.7,625$ & & & \\
\hline
\end{tabular}

Due to the time-varying stiffness, the gear meshing effect can be regarded as inner excitations to some extent, and thus the vibration characteristic of the entire system became complex, which can be identified from the abundant frequency components of both vibration spectra. Experimental frequencies from the front chassis mainly concentrated on $62.5 \mathrm{~Hz}, 114.4 \mathrm{~Hz}, 156.3 \mathrm{~Hz}, 312.5 \mathrm{~Hz}, 625 \mathrm{~Hz}$, etc., while the main frequencies of the output shaft were $62.5 \mathrm{~Hz}, 156.3 \mathrm{~Hz}, 312.5 \mathrm{~Hz}, 479.1 \mathrm{~Hz}, 500.2 \mathrm{~Hz}, 625 \mathrm{~Hz}$, etc. Detailed comparisons from the figures and tables show that the major frequency components and corresponding amplitudes of the experimental results were in accordance with the simulated ones; thus, validation of the dynamic modeling method and the WTG model is demonstrated.

\subsection{Time-Domain Dynamic Results of the WTG}

Figures 11-13 are the numerical time-domain dynamic meshing forces between the sun and planet gears of the LSP and HSP, and the meshing force of the PSH, respectively.
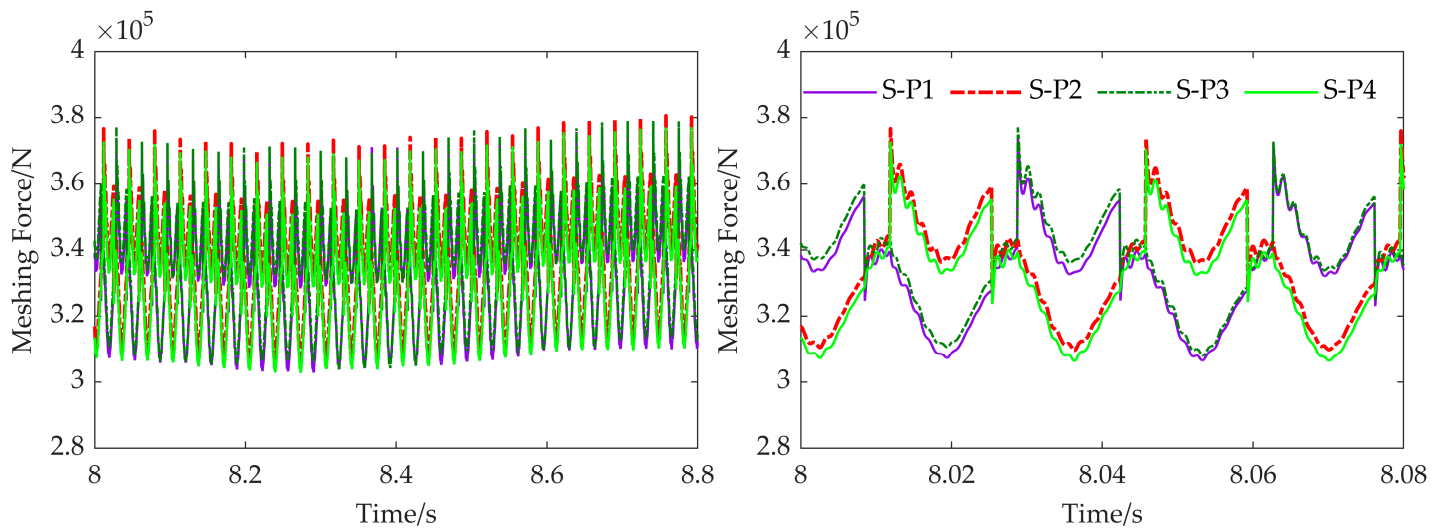

Figure 11. Meshing force between the sun and the four planet gears of the LSP.
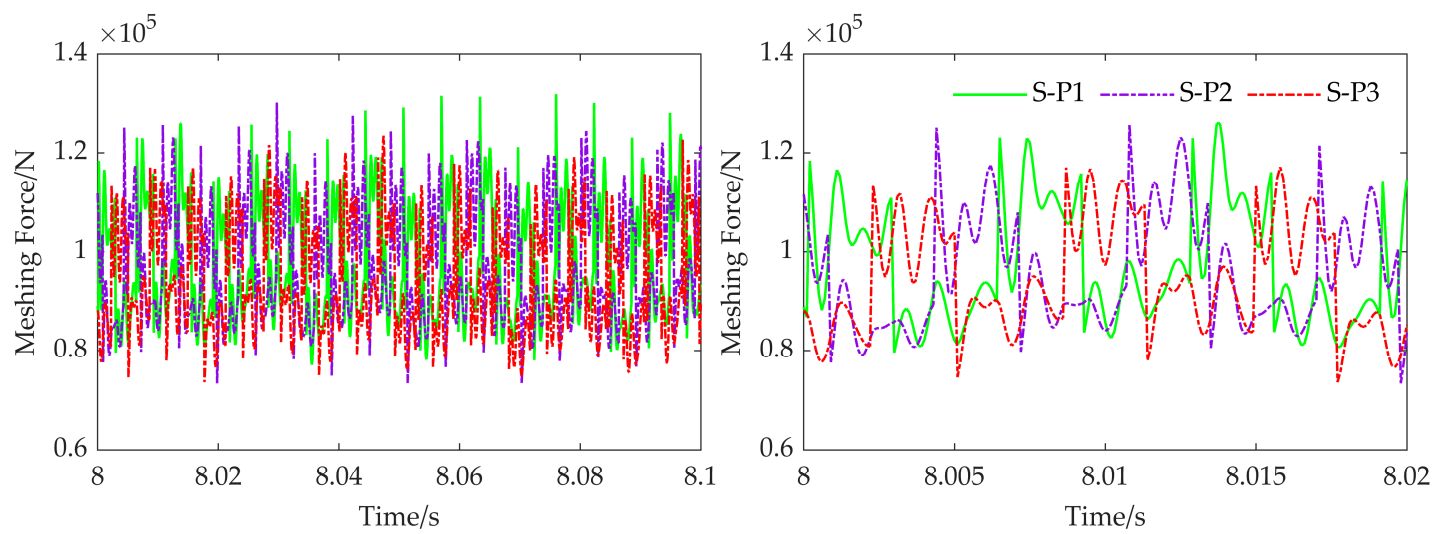

Figure 12. Meshing force between the sun and the three planet gears of the HSP. 

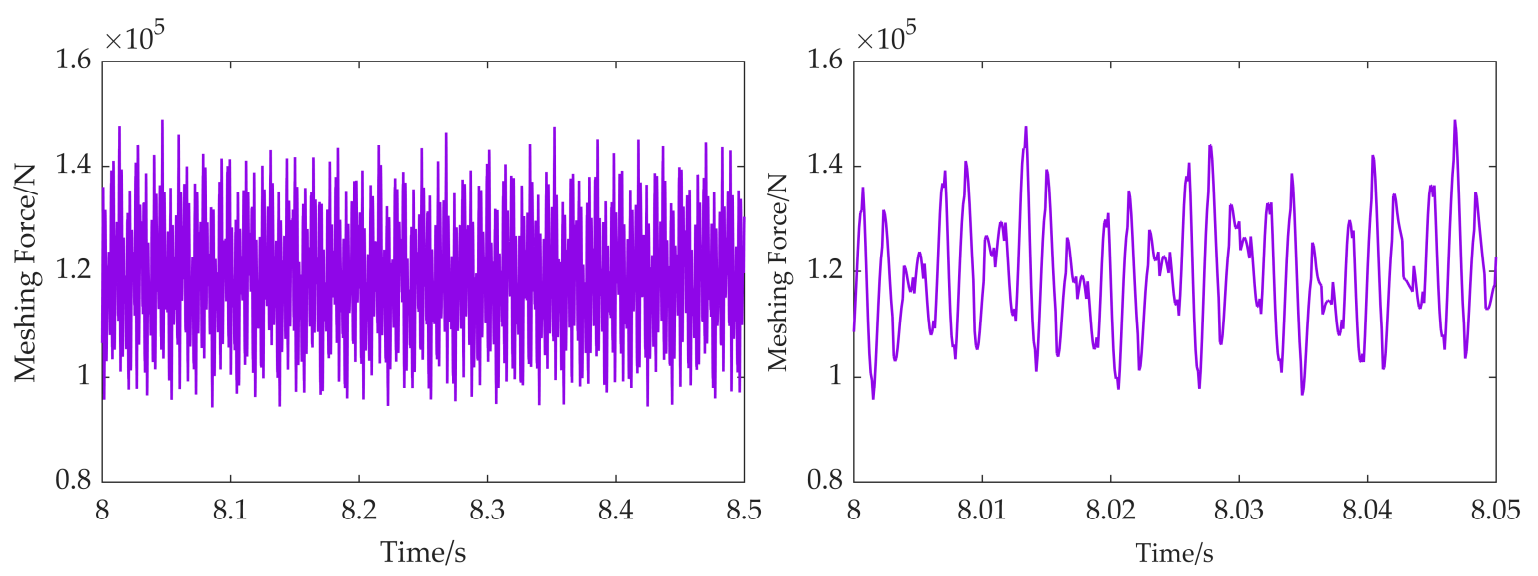

Figure 13. Meshing force between the input and output gears of the PSH.

On this basis, the dynamic loading factors between gears, which are significant for the design stage, were calculated to be 1.12, 1.37 and 1.27 and are listed in Table 9. The results were different from the chosen factors of 1.02, 1.08, 1.07 obtained from an experiential manual. Under larger dynamic loadings that exceed the design limits, gear cracks may occur. Further dynamic examinations of the whole system in both the frequency and time domains can be conducted using the proposed method, while these examinations are beyond the scope of the existing method.

Table 9. Dynamic loading factors of the gear system.

\begin{tabular}{ccc}
\hline Position & Load Fluctuation $\left(\times \mathbf{1 0}^{\mathbf{5}} \mathbf{N}\right)$ & Dynamic Loading Factor \\
\hline LSP: planet-sun & $3.34 \pm 0.39$ & 1.118 \\
LSP: planet-ring & $3.55 \pm 0.47$ & 1.134 \\
HSP: planet-sun & $0.97 \pm 0.36$ & 1.373 \\
HSP: planet-ring & $0.98 \pm 0.34$ & 1.349 \\
PSH: input-output & $1.09 \pm 0.29$ & 1.268 \\
\hline
\end{tabular}

\section{Conclusions}

In this paper, a novel and generally applicable LTC modeling approach for calculating the dynamic behavior of heavy-duty gearboxes in the time domain with consideration of the floating effect, time-varying meshing stiffness, bearing stiffness, torsional stiffness, etc., is proposed. This approach is more comprehensive and apparently gives clearer insights into the time-domain dynamics of heavy-duty gearboxes, such as WTGs, than the existing method. Based on the proposed method, a LTC model of a full test rig was built, which was used to test a 2 MW WTG consisting of two planetary gear sets and a parallel-shaft helical gear set. Dynamic experiments were conducted on the test rig. Validity of the proposed method and the built model were demonstrated, as the simulated results were in accordance with the experimental results. According to the time-domain results of meshing forces in the verified model, larger dynamic loading factors than the designed ones chosen by a traditional empirical method were found. This means that gear damage may occur in actual working conditions and the built 2 MW WTG system must be redesigned and improved. In conclusion, the proposed method can give a new perspective on heavy-duty gearboxes that is preferable to the existing method, and can provide sufficient time-domain information to contribute to the design, evaluation and redesign of large-scale mechanical systems as represented by WTG systems. 
Author Contributions: Conceptualization, J.W., W.J. and X.C.; Data curation, W.J.; Formal analysis, Y.Z.; Funding acquisition, W.J.; Investigation, J.W. and Y.Z.; Methodology, J.W., Y.Z. and W.J.; Project administration, X.C.; Resources, X.C.; Visualization, Y.Z.; Writing-original draft, J.W. All authors have read and agreed to the published version of the manuscript.

Funding: This work was supported by the National Key R\&D Program of China (No.2020YFB2007301, No.2020YFB2007601), the National Natural Science Foundation of China (No.52075193), and the National Science and Technology Major Project of China (No.2017ZX02101007-002).

Institutional Review Board Statement: Not applicable.

Informed Consent Statement: Not applicable.

Data Availability Statement: Data are contained within the article.

Conflicts of Interest: The authors declare no conflict of interest.

\section{Nomenclature}

Symbol/Abbreviation
LTC
MW
WTG
DOF
LSP
HSP
PSH
FEA
$x_{R}, y_{R}$
$x_{S}, y_{S}$
$x_{C}, y_{C}$
$\theta_{R}, \theta_{S}, \theta_{C}$
$x_{P}^{i}, y_{P}^{i}, \theta_{P}^{i}$
$N_{R P}^{i}, f_{R P}^{i}$
$N_{S P}^{i}, f_{S P}^{i}$
$F_{C P}^{i}, T_{C P}^{i}$
$O_{S}, O_{P}^{i}, O_{R}$
$\gamma_{P S}^{i}$
$\gamma_{P S 0}^{i}$
$\Delta \gamma_{P S}^{i}$
$Z_{S}, Z_{P}, Z_{R}$
$\theta_{P}^{\prime i}-P S$
$\Delta \theta_{P-P S}^{i}$
$\delta_{\theta n-P S}^{i}$
$d_{P S}^{i}$
$d_{P S 0}^{i}$
$\Delta d_{P S}^{i}$
$r_{P}^{i}-P S$
$\alpha_{P S}^{i}$
$r_{P b}, r_{S b}, r_{C b}$
$\delta_{d n-P S}^{i}$
$\delta_{n-P S}^{i}$
$\delta_{t-P S}^{i}$

\section{Description}

Lateral-torsional coupling (model/modeling)

Megawatt

Wind turbine gearbox

Degrees of freedom

Low-speed planetary gear set

High-speed planetary gear set

Parallel-shaft helical gear set

Finite element analysis

Translational displacements of the ring gear

Translational displacements of the sun gear

Translational displacements of the carrier

Rotational angles of the ring gear, sun gear and carrier respectively Translational displacements and rotational angle of the $i$ th planet gear

Normal pressure force and tangential force exerted on the $i$ th planet gear by the ring gear

Normal pressure force and tangential force exerted on the $i$ th planet gear by the sun gear

Reaction force and torque exerted on the $i$ th planet gear by the bearing

Center points of the sun gear, the $i$ th planet gear, and the ring gear respectively

Time-varying position angle between the center connection line $O_{P}^{i} O_{S}$ and the $\mathrm{X}$ axis

Inital position angle between the center connection line $O_{P}^{i} O_{S}$ and the $X$ axis

Time-varying changing value of position angle $\gamma_{P S}^{i}$

Tooth number of the sun gear, planet gear, and ring gear respectively

Ideal rotational angle of the ith planet gear under $\theta_{P}$

Difference between the ideal and actual rotational angles of the ith planet gear

Linear deformation caused by angle difference $\Delta \theta_{P-P S}^{i}$

Time-varying center distance between the ith planet gear and the sun gear Initial center distance between the ith planet gear and the sun gear

Time-varying changing value of center distance $d_{P S}^{i}$

Pitch radius of the ith planet gear while engaged with sun gear

Engagement angle between the ith planet gear and sun gear

Radius of base circle of the planet gear, sun gear and ring gear respectively

Linear deformation caused by variation of center distance $\Delta d_{P S}^{i}$

Normal composite deformation between the ith planet and sun gear

Tangent composite deformation between the ith planet and sun gear 
$\xi$

$\varphi$

$\varphi_{S 0}$

$k_{P S}^{i}$

$\beta_{S P-N}^{i}$

$\mu_{P S}$

$c_{P S}$

$\beta_{S P-f}^{i}$

$d_{P R}^{i}$

$\gamma_{P R}^{i}$

$\gamma_{P R 0}^{i}$

$\Delta \gamma_{P R}^{i}$

$\theta_{P-P R}^{\prime i}$

$\triangle \theta_{P-P R}^{i}$

$\delta_{\theta n-P R}^{i}$

$d_{P R}^{i}$

$d_{P R 0}^{i}$

$\Delta d_{P R}^{i}$

$r_{P-P R}^{i}$

$\alpha_{P R}^{i}$

$\delta_{d n-P R}^{i}$

$\delta_{n-P R}^{i}$

$\delta_{t-P R}^{i}$

$k_{P R}$

$\beta_{R P-N}^{i}$

$\mu_{P R}$

$c_{P R}$

$\beta_{R P-f}^{i}$

$R_{P}$

$\gamma_{C P 0}^{i}$

$\delta_{C P-x}^{i}, \delta_{C P-y}^{i}$

$\delta_{C P-\theta}^{i}$

$k_{C P B}$

$d_{C P B}$

$\mu_{C P B}$

${ }^{{ }^{C}} \mathrm{CPB}$

$k_{S B}, c_{S B}$

$k_{R B}, c_{R B}$

$M_{a}, I_{a}, G_{a}(a=S, P, R, C)$

$T_{a(a=S, R, C)}$
Coefficient representing the double pair gear meshing stiffness with respect to single pair gear meshing stiffness

Initial phase angle of the ith planet gear

Phase difference of adjacent planet gears into a single tooth meshing state

Time-varying meshing stiffness of the ith planet gear and sun gear

Angle between the normal force $N_{S P}^{i}$ and the $\mathrm{X}$ axis

Coulomb friction coefficient of the sun gear and planet gear

Viscous damping coefficient of the sun gear and planet gear

Angle between the tangent friction force $f_{S P}^{i}$ and the $\mathrm{X}$ axis

Time-varying center distance between the ith planet gear and the ring gear

Time-varying position angle between the center connection line $O_{P}^{i} O_{R}$ and the $X$ axis

Inital position angle between the center connection line $O_{P}^{i} O_{R}$

and the $\mathrm{X}$ axis

Time-varying changing value of position angle $\gamma_{P R}^{i}$

Ideal rotational angle of the ith planet gear under $\theta_{R}$

Angle difference between the ideal and actual rotational angles of the ith planet gear

Linear deformation caused by angle difference $\Delta \theta_{P-P R}^{i}$

Time-varying center distance between the ith planet gear and the ring gear

Initial center distance between the ith planet gear and the ring gear

Time-varying changing value of center distance $d_{P R}^{i}$

Pitch radius of the ith planet gear while engaged with ring gear

Engagement angle between the ith planet gear and ring gear

Linear deformation caused by variation of center distance $\Delta d_{P R}^{i}$

Normal composite deformation between the ith planet and ring gear

Tangent composite deformation between the ith planet and ring gear

Meshing stiffness of the planet gear and sun gear

Angle between the normal force $N_{R P}^{i}$ and the $\mathrm{X}$ axis

Coefficient of coulomb friction of the ring gear and planet gear

Viscous damping coefficient of between the ring gear and planet gear

Angle between the tangent friction force $f_{R P}^{i}$ and the $\mathrm{X}$ axis

Distribution radius of planet gears

Initial distribution angle of the ith planet gear

Deformations of the ith planet relative to the carrier in $X$ and $Y$

directions respectively

Rotational angle of the ith planet relative to the carrier

Translational stiffness of the bearings between carrier and planet gear

Nominal diameter of bearings between carrier and planet gear

Coulomb friction coefficient of the bearings between carrier and planet gear

Viscous damping coefficient of the bearings between carrier and planet gear

Bearing stiffness and rotational viscous damping coefficient of the sun gear bearing

Bearing stiffness and rotational viscous damping coefficient of the ring gear bearing

Mass, inertia and gravity of the sun gear, planet gear, ring gear and carrier respectively

Torques on the sun gear, ring gear and carrier respectively

\section{References}

1. Helsen, J.; Vandepitte, D.; Desmet, W. Flexible modelling of wind turbine gearboxes with special focus on shaft flexibilities. In Proceedings of the 10th International Conference on Recent Advances in Structural Dynamics (RASD) 2010, Southampton, UK, 12-14 July 2010.

2. Tsai, S.; Hwang, G.; Yeh, S. An analytical approach for load sharing analysis of planetary gear drives. In Proceedings of the 13th World Congress in Mechanism and Machine Science, Guanajuato, Mexico, 19-23 June 2011; pp. 19-25.

3. Leithead, W.; Rogers, M. Drive-train characteristics of constant speed HAWT's: Part I-Representation by simple dynamic models. Wind Eng. 1996, 20, 149-174. 
4. Sicot, C.; Devinant, P.; Laverne, T.; Loyer, S.; Hureau, J. Experimental study of the effect of turbulence on horizontal axis wind turbine aerodynamics. Wind Energy 2006, 9, 361-370. [CrossRef]

5. Lee, G.H.; Park, Y.J.; Kim, J.K.; Yim, J.G.; Nam, Y.Y.; Chong, T.H. An optimal design for MW-class wind turbine gearboxes based on their structural characteristics. In Proceedings of the 8th World Wind Energy Conference and Exhibition 2009, Jeju, Korea, 23-25 June 2009; pp. 101-109.

6. Krouse, J. Wind turbine gearbox vibaration. Power Eng. 2009, 113, 16-17.

7. Spinato, F.; Tavner, P.J.; van Bussel, G.J.W.; Koutoulakos, E. Reliability of wind turbine subassemblies. IET Renew. Power Gener. 2009, 3, 387-401. [CrossRef]

8. Abderrazzaq, M.A.; Hahn, B. Analysis of the turbine standstill for a grid connected wind farm (case study). Renew. Energy 2006, 31, 89-104. [CrossRef]

9. Liang, X.H.; Zuo, M.J.; Hoseini, M.R. Vibration signal modeling of a planetary gear set for tooth crack detection. Eng. Fail. Anal. 2015, 48, 185-200. [CrossRef]

10. Li, M.; Xie, L.; Ding, L. Load sharing analysis and reliability prediction for planetary gear train of helicopter. Mech. Mach. Theory 2017, 115, 97-113. [CrossRef]

11. Kahraman, A. Load sharing characteristics of planetary transmissions. Mech. Mach. Theory 1994, 29, 1151-1165. [CrossRef]

12. Lin, J.; Parker, R.G. Analytical characterization of the unique properties of planetary gear free vibration. J. Vib. Acoust. 1999, 121, 316-321. [CrossRef]

13. Abousleiman, V.; Velex, P. A hybrid 3D finite element/lumped parameter model for quasi-static and dynamic analyses of planetary/epicyclic gear sets. Mech. Mach. Theory 2006, 41, 725-748. [CrossRef]

14. Abousleiman, V.; Velex, P.; Becquerelle, S. Modeling of spur and helical gear planetary drives with flexible ring gears and planet carriers. J. Mech. Des. 2007, 129, 95-106. [CrossRef]

15. Chen, Z.G.; Shao, Y.M. Dynamic simulation of planetary gear with tooth root crack in ring gear. Eng. Fail. Anal. 2013, 31, 8-18. [CrossRef]

16. Cooley, C.G.; Parker, R.G.; Vijayakar, S.M. A frequency domain finite element approach for three-dimensional gear dynamics. J. Vib. Acoust. 2011, 133, 041004. [CrossRef]

17. Maláková, S.; Puškár, M.; Frankovský, P.; Sivák, S.; Palko, M.; Palko, M. Meshing Stiffness-A Parameter Affecting the Emission of Gearboxes. Appl. Sci. 2020, 10, 8678. [CrossRef]

18. Maláková, S.; Urbanský, M.; Fedorko, G.; Molnár, V.; Sivak, S. Design of Geometrical Parameters and Kinematical Characteristics of a Non-circular Gear Transmission for Given Parameters. Appl. Sci. 2021, 11, 1000. [CrossRef]

19. Girsang, I.P.; Dhupia, J.S.; Muljadi, E.; Singh, M.; Pao, L.Y. Gearbox and Drivetrain Models to Study Dynamic Effects of Modern Wind Turbines. IEEE Trans. Ind. Appl. 2014, 50, 3777-3786. [CrossRef]

20. Jonkman, J.M.; Buhl, M.L., Jr. FAST User's Guide; Technical Report No NREL/EL-500-38230 2005; National Renewable Energy Laboratory: Golden, CO, USA, 2005.

21. Zhu, C.; Xu, X.; Lim, T.C.; Du, X.; Liu, M. Effect of flexible pin on the dynamic behaviors of wind turbine planetary gear drives. Proc. Inst. Mech. Eng. Part C J. Mech. Eng. Sci. 2013, 227, 74-86. [CrossRef]

22. Shenglin, Z.; Caichao, Z.; Chaosheng, S.; Jianjun, T.; Xu, C. Natural characteristic analysis of wind turbine drivetrain considering flexible supporting. Proc. Inst. Mech. Eng. Part C J. Mech. Eng. Sci. 2017, 232, 1-15. [CrossRef]

23. Park, Y.J.; Lee, G.H.; Song, J.S.; Nam, Y.Y. Characteristic Analysis of Wind Turbine Gearbox Considering Non-Torque Loading. J. Mech. Des. 2013, 135, 044501. [CrossRef]

24. Qin, D.T.; Song, C.S.; Lu, B.; Song, C.S.; Qin, D.T. Dynamic analysis of a heavy duty marine gearbox with gear mesh coupling. Proc. Inst. Mech. Eng. Part C J. Mech. Eng. Sci. 2009, 223, 2531-2547.

25. Liu, L.; Liang, X.; Zuo, M.J. Vibration signal modeling of a planetary gear set with transmission path effect analysis. Measurement 2016, 85, 20-31. [CrossRef]

26. Cooley, C.G.; Parker, R.G. A Review of Planetary and Epicyclic Gear Dynamics and Vibrations Research. Appl. Mech. Rev. 2014, 66, 040804. [CrossRef]

27. Guo, Y.; Keller, J.; Parker, R.G. Nonlinear dynamics and stability of wind turbine planetary gear sets under gravity effects. Eur. J. Mech. A Solids 2014, 47, 45-57. [CrossRef]

28. Chen, Z.G.; Zhu, Z.F.; Shao, Y.M. Fault feature analysis of planetary gear system with tooth root crack and flexible ring gear rim. Eng. Fail. Anal. 2015, 49, 92-103. [CrossRef]

29. Jiang, F.; Ding, K.; He, G.; Sun, Y.; Wang, L. Vibration fault features of planetary gear train with cracks under time-varying flexible transfer functions. Mech. Mach. Theory 2021, 158, 104237. [CrossRef]

30. Wang, C.; Parker, R.G. Dynamic modeling and mesh phasing-based spectral analysis of quasi-static deformations of spinning planetary gears with a deformable ring. Mech. Syst. Signal Process. 2020, 136, 106497. [CrossRef] 